\title{
Human Circadian Rhythm and Social Distancing in the COVID-19 Crisis
}

\author{
Heon-Jeong Lee ${ }^{1,2}$ \\ 'Department of Psychiatry, Korea University College of Medicine, Seoul, Korea \\ ${ }^{2}$ Chronobiology Institute, Korea University, Seoul, Korea
}

Social distancing is a set of non-pharmaceutical interventions and measures that may be recommended during pandemics. Social distancing is practiced to prevent the spread of a contagious disease by increasing the physical distance or reducing the number of times people come into close contact with each other [1]. Social distancing has become a strong shield in the fight against the virus causing coronavirus disease 2019 (COVID-19). To curtail the spread of COVID-19 and avoid overburdening the healthcare systems, several social distancing measures have been enforced, including closure of schools and workplaces, isolation, and restriction of public movement.

Although social distancing is effective to prevent COVID-19 transmission [2], it has various social, economic, and health problems. One of them is increasing the risk of circadian rhythm disturbances due to the loss of daily routine and irregular pattern of living. Therefore, practice of social distancing should not be the only emphasis. Concomitantly, it is important to maintain the daily routine of life and ensure regular circadian rhythms.

Maintaining the circadian rhythm is essential for good health. The circadian clock, which is found in almost every organ of the body and the brain, is pivotal for a well-functioning immune system. Synchronization of the circadian rhythms in the lungs, heart, liver, and brain ensure continuation of routine physiological processes. It also ensures the maintenance of a healthy immune system that can effectively fight and defeat the virus. Recent studies demonstrate the importance of circadian rhythms and sleep in

Received: May 14, 2020 Revised: May 18, 2020

Accepted: May 18, 2020

Corresponding author: Heon-Jeong Lee, MD, PhD, Department of Psychiatry, Korea University College of Medicine, 73 Goryeodae-ro, Seongbuk-gu, Seoul 02841 , Korea.

Tel: 82-2-920-6721, Fax: 82-2-929-7679, E-mail: leehjeong@korea.ac.kr

(a) This is an Open Access article distributed under the terms of the Creative Commons Attribution Non-Commercial License (https://creativecommons.org/ licenses/by-nc/4.0) which permits unrestricted non-commercial use, distribution, and reproduction in any medium, provided the original work is properly cited. immune homeostasis. Both innate and adaptive immune responses have a time-of-day-dependent functions [3]. Asynchrony of the biological clock degrades the effectiveness of the immune system. A disrupted circadian rhythm weakens the immune system, lowering the ability to defeat the virus [4].

Circadian rhythm disturbances-due to insufficient exposure to sunlight and inadequate lighting-are not restricted to prisons [5]. Social distancing also affects mental health. Limited social interactions can reduce nighttime activities and light exposure, which have somewhat positive effects on circadian rhythm. However, spending prolonged days or weeks at home with limited resources, stimuli, and social contacts can adversely impact mental health due to circadian rhythm disturbance. During the COVID-19 pandemic, there are many voices of concern about the increase in suicide rates [6]. Increased number of suicides may be attributable to economic stress, social isolation, limited access to communication, and seasonal factors. However, emotional disturbance due to impaired daily routines and ensuing circadian rhythm disturbance should also be considered. Insufficient exposure to morning sunlight could delay the circadian rhythm, leading to an increased risk of depression and suicide [7]. Even during social distancing, waking up early in the morning and enjoying the sun light or outdoor walks should be encouraged by the concerned authorities for holistic public welfare.

\section{Acknowledgments}

None

\section{Conflicts of Interest}

The author has no potential conflicts of interest to disclose.

\section{ORCID iD}

Heon-Jeong Lee (1)

https://orcid.org/0000-0002-9560-2383 


\section{REFERENCES}

1. Ahmed F, Zviedrite N, Uzicanin A. Effectiveness of workplace social distancing measures in reducing influenza transmission: a systematic review. BMC Public Health 2018;18:518.

2. Mahase E. Covid-19: South Korea relaxes social distancing after the number of new cases drops below 10 a day. BMJ 2020;369:m1842.

3. Haspel JA, Anafi R, Brown MK, Cermakian N, Depner C, Desplats P, et al. Perfect timing: circadian rhythms, sleep, and immunity - an NIH workshop summary. JCI Insight 2020;5:e131487.

4. Panda S. Beyond sanitizing and social distancing - a healthy circadian rhythm may keep you sane and increase resilience to fight COVID-19.
Available at: https://theconversation.com/beyond-sanitizing-and-social-distancing-a-healthy-circadian-rhythm-may-keep-you-sane-and-increase-resilience-to-fight-covid-19-135535. Accessed May 2, 2020.

5. Khan ZA, Chattoraj A. Artificial illumination in the prison: general recommendation for prisoner and associated staffs. Chronobiol Med 2019;1:131131.

6. Reger MA, Stanley IH, Joiner TE. Suicide mortality and coronavirus disease 2019-a perfect storm? JAMA Psychiatry 2020 Apr 10 [Epub]. Available at: https://doi.org/10.1001/jamapsychiatry.2020.1060.

7. Lee HJ. Circadian misalignment and bipolar disorder. Chronobiol Med 2019;1:132-136. 